\title{
Teores foliares de macronutrientes em crisântemos cultivados em substratos contendo composto de lixo urbano e casca de arroz carbonizada ${ }^{1}$
}

\author{
ÂNGELA CRISTINA OLIVEIRA STRINGHETA², HERMÍNIA PRIETO MARTINEZ ${ }^{3}$, \\ ANTÔNIO AMÉRICO CARDOSO ${ }^{4}$ e CÂNDIDO ALVES DA COSTA ${ }^{5}$
}

\section{RESUMO}

O objetivo deste trabalho foi investigar a influência da adição de composto de lixo urbano (CLU) e de casca de arroz carbonizada (CAC) no crescimento e nos teores foliares de macronutrientes, em duas variedades de crisântemo (Dendranthema grandiflora Tzvelev) (Amarelo São Paulo e Puritan) cultivadas em substrato. Os tratamentos foram constituídos da mistura solo-areia-condicionador, na proporção volumétrica 2:1:4, constituindo-se o condicionador da mistura CAC + CLU, em que: $\mathrm{T}_{1}=100 \% \mathrm{CAC} ; \mathrm{T}_{2}=67 \% \mathrm{CAC}+33 \%$ $\mathrm{CLU} ; \mathrm{T}_{3}=33 \% \mathrm{CAC}+67 \% \mathrm{CLU}$, e $\mathrm{T}_{4}=100 \% \mathrm{CLU}$. Cultivaram-se plantas em vasos e colheram-nas, parceladamente, à medida que cada tratamento apresentava $70 \%$ das inflorescências abertas, e determinaram-se as concentrações foliares dos macronutrientes. Variações na concentração do CLU e da CAC influenciaram as concentrações foliares de $\mathrm{N}, \mathrm{P}$ e $\mathrm{Ca}$, com o teor máximo de $\mathrm{N}$ e $\mathrm{P}$ foliares alcançados com $33 \%$ de CLU, como condicionador, e os teores máximos de $\mathrm{Ca}$ e $\mathrm{Mg}$ atingidos com $67 \%$ e $100 \%$ de CLU respectivamente. A absorção dos nutrientes pelas plantas foi influenciada pelo elevado $\mathrm{pH}(>7,4)$ e pela elevada condutividade elétrica $(>12,97 \mathrm{dS} / \mathrm{m})$ apresentada pelos substratos contendo CLU. A concentração de K não foi influenciada pela concentração de CLU e CAC, mantendo-se constante para todos os tratamentos. Não se observaram sintomas de toxicidade nas plantas.

Palavras-chaves: Dendranthema grandiflora Tzvelev, substrato, nutrição.

\begin{abstract}
Leaf macronutrient contents in chrysanthemum grown in substrate containing urban solid waste compost and carbonized rice rusk

This study was carried out to investigate the influence of adding urban solid waste compost (CLU) combined with carbonized rice husk (CAC) on the growth and content of leaf macronutrients $(\mathrm{N}, \mathrm{P}, \mathrm{K}, \mathrm{Ca}$ and $\mathrm{Mg}$ ) in two chrysanthemum (Dendranthema grandiflora Tzvelev) varieties Amarelo São Paulo and Puri$\tan$. The treatments were constituted of a soil-sand-conditioner mixture $(2: 1: 4$ volumetric proportion) with the mixture conditioner being CAC + CLU, where $\mathrm{T}_{1}=$ $100 \% \mathrm{CAC} ; \mathrm{T}_{2}=67 \% \mathrm{CAC}+33 \% \mathrm{CLU} ; \mathrm{T}_{3}=33 \%$ $\mathrm{CAC}+67 \% \mathrm{CLU}$ and $\mathrm{T}_{4}=100 \% \mathrm{CLU}$. The plants were grown in pots and harvested in parcels as each treatment presented $70 \%$ opened inflorescence. The leaf concentrations of the studied macronutrients were determined. Variations in CLU and CAC concentrations affected the leaf concentrations of $\mathrm{N}, \mathrm{P}$ and $\mathrm{Ca}$, with the maximum leaf $\mathrm{N}$ and $\mathrm{P}$ contents being reached at 33\% CLU, as conditioner, and the maximum $\mathrm{Ca}$ and $\mathrm{Mg}$ contents at $66 \%$ and $100 \%$ CLU, respectively. The absorption of nutrients by the plants was influenced by a high $\mathrm{pH}(>7.4)$ and electric conductivity $(>12.97 \mathrm{dS} / \mathrm{m})$ presented by the substrates containing CLU. K concentration was not affected by CLU and CAC concentrations, remaining constant in all the treatments. No toxicity symptoms were observed in the plants.
\end{abstract}

Key words : Dendranthema grandiflora Tzvelev, substrate, nutrition.

\footnotetext{
${ }^{1}$ Trabalho desenvolvido no Setor de Floricultura do Departamento de Fitotecnia da Universidade Federal de Viçosa (UFV).

${ }^{2}$ Engenheira Agrônoma, MS, Professora Assistente, UFV, 36571-000 Viçosa (MG).

${ }^{3}$ Engenheira Agrônoma, DS, Professora Adjunta, UFV, 36571-000 Viçosa (MG).

${ }^{4}$ Engenheiro Agrônomo, DS, Professor Titular, UFV, 36571-000 Viçosa (MG).

${ }^{5}$ Engenheiro Agrônomo, MS, Professor Assistente, Núcleo de Ciências Agrárias, UFMG, 39404-006 Montes Claros (MG).
} 


\section{INTRODUÇÃO}

O crisântemo (Dendranthema grandiflora Tzvelev) é uma das flores mais comercializadas no mercado brasileiro, ocupando o segundo lugar em volume de comercialização. Os solos não satisfazem, simultaneamente, aos requerimentos de boa aeração, boa retenção de água e boa disponibilidade de nutrientes, indispensáveis ao bom desenvolvimento da cultura, o que torna necessária a adição de material orgânico e inorgânico, compondo substratos de cultivo.

A escolha do resíduo orgânico ou inorgânico é função da sua disponibilidade, variando, portanto, com as regiões e com a cultura, além dos aspectos econômicos. Os mais utilizados em floricultura são a casca de arroz carbonizada (SOUZA, 1991; STRINGHETA et al., 1996), casca de pínus (ou outras árvores), perlita, vermiculita e turfa. A casca de arroz vem sendo particularmente recomendada para o cultivo de diversas variedades de crisântemo, tanto no cultivo de flores como na produção de mudas. SOUZA (1991), estudando componentes e proporções para substratos, concluiu que a mistura solo: areia: casca de arroz carbonizada (CAC), na proporção 2:1:4, melhorou a qualidade e aumentou a produtividade de crisântemos cultivados em vaso.

Na região de Viçosa, não existem áreas cultivadas com arroz; assim, sua casca é um resíduo caro e de difícil aquisição.

Por outro lado, várias usinas de compostagem de lixo urbano vêm sendo instaladas no município de Viçosa e na região da Zona da Mata Mineira, o que torna o composto de lixo um resíduo disponível a um custo muito baixo (algumas usinas doam tais resíduos). Dessa forma, torna-se importante a pesquisa de seu aproveitamento como alternativa de produção de substratos mais baratos, paralelamente à redução dos problemas ambientais ocasionados por seu acúmulo, resultante de seu não-uso. O lixo é um material utilizável como substrato, desde que transformado em composto orgânico, podendo, em mistura, melhorar as propriedades químicas, físicas e biológicas dos substratos (KIEHL, 1985).

A transformação do lixo urbano em composto (CLU) não é solução definitiva, pois a presença de metais pesados pode torná-lo inviável para muitos casos, como a produção de alimentos. Na produção de plantas ornamentais, esse risco é reduzido, pelo fato de elas não serem utilizadas, na maioria das vezes, na alimentação humana ou animal.
A concentração de um nutriente na planta é indicador final de vários fatores que influenciam seu crescimento, sendo inquestionável a contribuição da análise foliar para avaliar a qualidade da produção agrícola e como alerta aos produtores quanto à necessidade de suplementação de nutrientes para aumentar ou melhorar a produção. A substituição da casca de arroz carbonizada pelo composto de lixo urbano resulta em alterações na composição química dos substratos, influenciando a disponibilidade de nutrientes para as plantas.

O objetivo deste trabalho foi investigar a influência da adição de composto de lixo urbano (CLU) e de casca de arroz carbonizada (CAC) no crescimento (expresso em peso da matéria fresca e matéria seca das folhas) e no teor de macronutrientes foliares em duas variedades de crisântemo (Amarelo São Paulo e Puritan) cultivadas em substrato.

\section{MATERIAL E MÉTODOS}

O experimento foi realizado em casa de vegetação, em Viçosa (MG), de abril a maio, utilizando-se duas variedades de crisântemo (Dendranthema grandiflora Tzvelev), Amarelo São Paulo e Puritan, próprias para o cultivo em vaso.

Com a finalidade de caracterizar os substratos, efetuaram-se análises químicas dos componentes das misturas (solo, casca de arroz carbonizada e composto de lixo urbano) e análise granulométrica do solo (Tabela 1), e estabeleceram-se quatro substratos com a mistura solo:areia:condicionador, na proporção volumétrica 2:1:4. O condicionador constituiu-se de casca de arroz carbonizada (CAC) e composto de lixo urbano (CLU), sendo os quatro tratamentos assim estabelecidos: $\mathrm{T}_{1}=$ $100 \% \mathrm{CAC} ; \mathrm{T}_{2}=67 \% \mathrm{CAC}+33 \% \mathrm{CLU} ; \mathrm{T}_{3}=33 \%$ $\mathrm{CAC}+67 \%$ CLU e $\mathrm{T}_{4}=100 \%$ CLU. Para homogeneização do tamanho das partículas, todos os componentes do substrato foram passados em peneira de $4 \mathrm{~mm}$. Antes do plantio, procederam-se, nos substratos, às análises químicas e à determinação do pH em água (na proporção 1:2,5) e da condutividade elétrica (CE) do extrato aquoso, na proporção 2:1, em temperatura próxima a $25^{\circ} \mathrm{C}$ (EMBRAPA, 1997) (Tabela 2).

A correção do solo foi realizada 20 dias antes do plantio, com aplicação de carbonato de cálcio e carbonato de magnésio P.A., na proporção estequiométrica 4:1, com base na fórmula: $2 \mathrm{Al}^{3+}+\left[2-\left(\mathrm{Ca}^{2+}+\mathrm{Mg}^{2+}\right)\right]$. 
Tabela 1. Características químicas do solo, casca de arroz carbonizada e do composto de lixo urbano e análise granulométrica do solo utilizados como substratos

\begin{tabular}{|c|c|c|c|}
\hline Características & Solo & $\begin{array}{c}\text { Casca de } \\
\text { arroz } \\
\text { carbonizada }\end{array}$ & $\begin{array}{c}\text { Composto } \\
\text { de lixo } \\
\text { urbano }\end{array}$ \\
\hline $\mathrm{pH} \mathrm{H}_{2} \mathrm{O} 1: 2,5$ & 4,8 & 7,0 & 8,00 \\
\hline $\mathrm{P}(\mathrm{mg} / \mathrm{kg})^{1}$ & 9,0 & 11,0 & 31,00 \\
\hline $\mathrm{Al}^{3+}\left(\mathrm{cmol}_{\mathrm{c}} / \mathrm{kg}\right)^{1}$ & 0,6 & 0,0 & 0,00 \\
\hline $\mathrm{Ca}^{2+}\left(\mathrm{cmol}_{\mathrm{c}} / \mathrm{kg}\right)^{2}$ & 0,4 & 2,2 & 3,60 \\
\hline $\mathrm{Mg}^{2+}\left(\mathrm{cmol}_{\mathrm{c}} / \mathrm{kg}\right)^{2}$ & 0,1 & 1,3 & 1,00 \\
\hline $\mathrm{H}+\mathrm{Al}(\mathrm{cmol} / \mathrm{kg})^{3}$ & 0,3 & 1,5 & 0,00 \\
\hline S.B. $\left(\mathrm{cmol}_{\mathrm{c}} / \mathrm{kg}\right)$ & 0,56 & 8,48 & 5,23 \\
\hline CTC efetiva $\left(\mathrm{cmol}_{\mathrm{c}} / \mathrm{kg}\right)$ & 1,16 & 8,58 & 52,30 \\
\hline CTC total $\left(\mathrm{cmol}_{\mathrm{c}} / \mathrm{kg}\right)$ & 3,56 & 9,98 & 52,30 \\
\hline Carbono total $(\%)$ & - & 22,70 & 13,64 \\
\hline $\mathrm{N}$ total $(\%)$ & - & 3,21 & 3,06 \\
\hline Relação C/N & - & - & 4,00 \\
\hline Areia grossa $(\%)^{4}$ & 14 & - & - \\
\hline Areia fina $(\%)^{4}$ & 13 & - & - \\
\hline Silte $(\%)^{4}$ & 7 & - & - \\
\hline Argila $(\%)^{4}$ & 66 & - & - \\
\hline Classificação textural & Muito argiloso & - & - \\
\hline
\end{tabular}

${ }^{1}$ Extrator Mehlich-1 (DEFELIPO \& RIBEIRO, 1996).

${ }^{2}$ Extrator KCl 1N (DEFELIPO \& RIBEIRO, 1996).

${ }^{3}$ Extraído com acetato de cálcio $1 \mathrm{~N}, \mathrm{pH} 7,0$.

${ }^{4}$ Método da pipeta, dispersão NaOH $1 \mathrm{~N}$ (EMBRAPA, 1997).
Na adubação pré-plantio, utilizou-se 1,5 g de adubo 4-14-8 por litro de solo e, durante o ciclo da cultura, realizou-se fertirrigação contendo $100 \mathrm{mg} / \mathrm{L}$ de $\mathrm{N}$ e 70 $\mathrm{mg} / \mathrm{L}$ de K, fornecidos na forma de sulfato de amônio e cloreto de potássio P.A. Ao final do experimento, aplicaram-se $370 \mathrm{mg} /$ vaso de sulfato de amônio e $280 \mathrm{mg} /$ vaso de cloreto de potássio resultantes da adição de 40 $\mathrm{ml}$ de solução/vaso/dia. Os micronutrientes foram fornecidos em duas pulverizações, com $3 \mathrm{ml} / \mathrm{L}$ de uma solução contendo: $\mathrm{Co}-0,0005 \%$, B - 0,02\%, Zn - 0,05\% e $\mathrm{Fe}-0,1 \%$, aos 30 e aos 45 dias após o plantio.

Foram desenvolvidas duas plantas por vaso, com capacidade de $500 \mathrm{ml}$, sendo cada uma delas submetida a duas despontas apicais, de forma a produzir 6 inflorescências por planta (12 inflorescências por vaso). Colheram-se as plantas quando, aproximadamente, $70 \%$ das inflorescências apresentavam-se abertas.

Para determinação do $\mathrm{N}$ orgânico, o material vegetal foi submetido à digestão sulfúrica, seguida de avaliação colorimétrica, utilizando o reagente de Nessler. Na determinação dos outros elementos estudados, o material vegetal foi submetido à digestão nítrico-perclórica, determinandos-se o $\mathrm{P}$ por colorimetria, conforme descrito por BRAGA \& DEFELIPO (1974); o $\mathrm{K}$, por fotometria de chama, e o $\mathrm{Ca}$ e o $\mathrm{Mg}$, por espectrofotometria de absorção atômica.

Tabela 2. Características químicas dos substratos que constituíram os tratamentos ${ }^{1}$, determinadas após adubação pré-plantio

\begin{tabular}{|c|c|c|c|c|}
\hline Características & $\mathrm{T}_{1}$ & $\mathrm{~T}_{2}$ & $\mathrm{~T}_{3}$ & $\mathrm{~T}_{4}$ \\
\hline $\mathrm{pH} \mathrm{H} \mathrm{H}_{2} \mathrm{O}: 2,5$ & 5,30 & 7,40 & 8,10 & 8,40 \\
\hline $\mathrm{P}(\mathrm{mg} / \mathrm{kg})^{2}$ & 20,00 & 71,00 & 172,00 & 191,00 \\
\hline $\mathrm{K}(\mathrm{mg} / \mathrm{kg})^{2}$ & 458,00 & 897,00 & 1370,00 & 1545,00 \\
\hline $\mathrm{Al}^{3+}\left(\mathrm{cmol}_{\mathrm{c}} / \mathrm{kg}\right)^{2}$ & 0,00 & 0,00 & 0,00 & 0,00 \\
\hline $\mathrm{Ca}^{2+}\left(\mathrm{cmol}_{\mathrm{c}} / \mathrm{kg}\right)^{3}$ & 2,30 & 6,10 & 7,30 & 7,90 \\
\hline $\mathrm{Mg}^{2+}\left(\mathrm{cmol}_{\mathrm{c}} / \mathrm{kg}\right)^{3}$ & 0,70 & 0,80 & 0,90 & 0,90 \\
\hline $\mathrm{H}+\mathrm{Al}\left(\mathrm{cmol}_{\mathrm{c}} / \mathrm{kg}\right)^{4}$ & 1,50 & 0,90 & 0,30 & 0,30 \\
\hline S.B. $\left(\mathrm{cmol}_{\mathrm{c}} / \mathrm{kg}\right)$ & 4,14 & 9,16 & 11,69 & 12,75 \\
\hline CTC efetiva $\left(\mathrm{cmol}_{\mathrm{c}} / \mathrm{kg}\right)$ & 4,14 & 9,16 & 11,69 & 12,75 \\
\hline CTC total $\left(\mathrm{cmol}_{\mathrm{c}} / \mathrm{kg}\right)$ & 5,64 & 10,06 & 11,99 & 13,05 \\
\hline Condutividade elétrica (dS/m) & 5,03 & 12,97 & 14,81 & 18,60 \\
\hline
\end{tabular}

\footnotetext{
${ }^{1} \mathrm{~T}_{1}=100 \%$ casca de arroz carbonizada (CAC) como condicionador.

$\mathrm{T}_{2}=67 \% \mathrm{CAC}+33 \%$ composto de lixo urbano (CLU) como condicionador.

$\mathrm{T}_{3}=33 \% \mathrm{CAC}+67 \%$ CLU como condicionador.

$\mathrm{T}_{4}=100 \%$ CLU como condicionador.

${ }^{2}$ Extrator Mehlich-1 (DEFELIPO \& RIBEIRO, 1996).

${ }^{3}$ Extrator KCl 1N (DEFELIPO \& RIBEIRO, 1996).

${ }^{4}$ Extraído com acetato de cálcio $1 \mathrm{~N}, \mathrm{pH} 7,0$.
} 
Avaliou-se a produção de matéria fresca e matéria seca das folhas, destacando-se estas do caule e acondicionando-as em sacos de papel kraft para secagem em estufas com temperatura de, aproximadamente, $65^{\circ} \mathrm{C}$ até atingir peso constante .

O experimento foi desenvolvido no esquema fatorial 4 x 2, em blocos casualizados com cinco repetições, constituído por quatro substratos e duas variedades. Procedeu-se à análise da variância, complementada com análises de regressão, das concentrações foliares de $\mathrm{N}, \mathrm{P}, \mathrm{K}, \mathrm{Ca}$ e $\mathrm{Mg}$ das plantas de crisântemo, em função da concentração do CLU e da CAC, como condicionadores.

\section{RESULTADOS E DISCUSSÃO}

A produção de matéria fresca (MFFo) e de matéria seca (MSFo) das folhas aumentou com a elevação do CLU, no substrato, até valores, estimados, próximos a $45 \%$ e a $50 \%$ de CLU respectivamente; acima dessa concentração, houve redução na produção de MFFo e MSFo, nas duas variedades estudadas (Figura 1).

Por outro lado, os teores de N, P, Ca e Mg variaram com a concentração de CLU adicionada ao condicionador, segundo função quadrática para N, P e Ca e, linear, para $\mathrm{Mg}$ (Figura 2). Apesar de as concentrações de $\mathrm{P}$ e Ca aumentarem, respectivamente, de 20 para 191
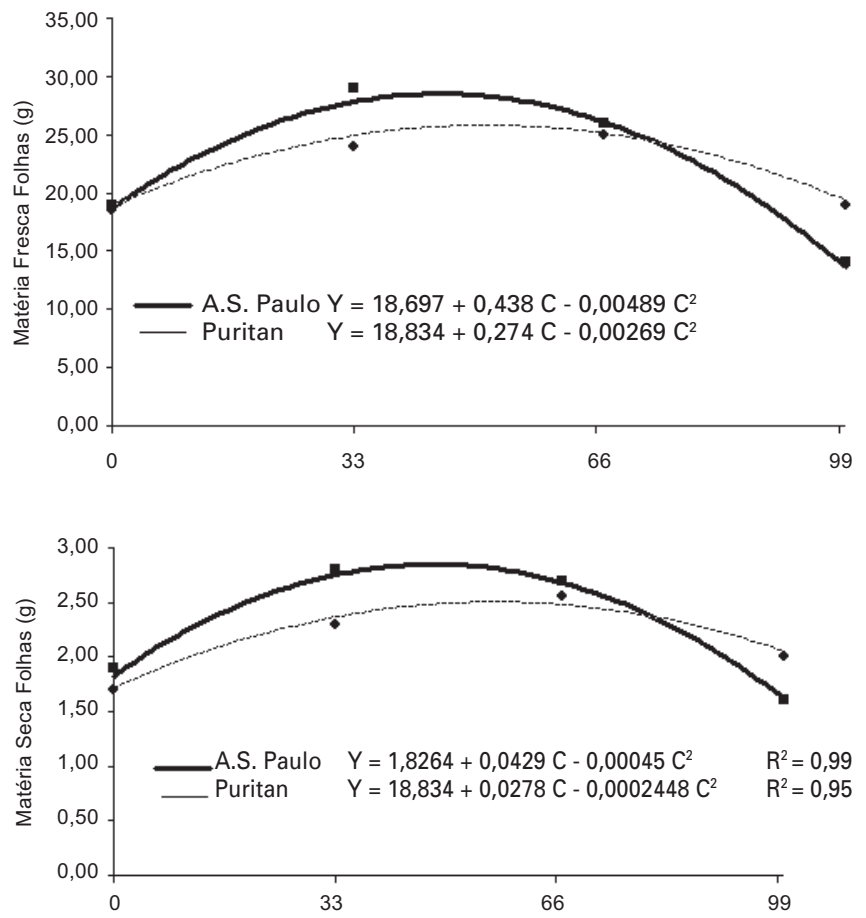

Figura 1. Peso de matéria fresca e matéria seca das folhas de crisântemo var. Amarelo São Paulo e Puritan, em função da concentração do CLU e da CAC como condicionadores. $\mathrm{mg} / \mathrm{dm}^{3}$ e de 2,30 para 7,90 $\mathrm{cmol}_{\mathrm{c}}$ com o aumento da proporção de CLU (Tabela 2), a concentração máxima desses nutrientes nas folhas ocorreu com $37,17 \%$ de CLU para o $\mathrm{P}$ e $70,7 \%$ de CLU para o Ca (Figura 2). Para o $\mathrm{Mg}$, cuja concentração nos substratos variou de 0,70 a $0,90 \mathrm{cmol}_{\mathrm{c}}$ (Tabela 2), o ponto de máxima concentração foliar estimado ficou fora do intervalo experimental (Figura 2), e para o N, cujo experimento foi de $74 \mathrm{mg} /$ vaso, situou-se em 26,92\% de CLU.

$\mathrm{O}$ teor foliar de $\mathrm{P}$ apresentou um comportamento muito semelhante ao da produção de matéria fresca e matéria seca foliar, mostrando uma relação direta entre as duas características avaliadas.

$\mathrm{O}$ teor de $\mathrm{K}$ manteve-se constante, independentemente da concentração de CLU e CAC utilizada como condicionadores (Figura 2), embora o incremento da concentração de CLU tenha resultado em incrementos na concentração de K disponível nos substratos de 458 (0\% CLU) para $1545 \mathrm{mg} / \mathrm{dm}^{3}$ (100\% CLU) (Tabela 2). Peterson, citado por NELSON (1991), verificou que a disponibilidade de $\mathrm{K}$ em substratos ricos em matéria orgânica praticamente não era influenciada pelo $\mathrm{pH}$ dos substratos, o que está de acordo com os resultados obtidos neste experimento.

As variedades de crisântemo estudadas não mostraram concentrações diferentes entre si para N, P, K e $\mathrm{Ca}$, quando submetidas a diferentes concentrações de CLU e CAC no substrato; diferiram, porém, quanto às concentrações de $\mathrm{Mg}$ (Figura 2) com concentrações foliares maiores para a variedade Amarelo São Paulo.

Observaram-se, ainda, que as concentrações foliares máximas para $\mathrm{N}$ e $\mathrm{P}(43,6 \mathrm{~g} / \mathrm{kg}$ e $3,45 \mathrm{~g} / \mathrm{kg})$ foram atingidas quando as concentrações de CLU, como condicionador, eram de 26,92 e 37,17, correspondendo a valores próximos a 33\% de CLU. Por outro lado, para $\mathrm{Ca}$ e $\mathrm{Mg}$, os teores máximos foliares foram alcançados com valores próximos a $67 \%$ e $100 \%$ de CLU, respectivamente, para as duas variedades. Esses resultados tornam difícil uma conclusão a respeito da melhor proporção dos condicionadores a utilizar.

Segundo KÄMPF (2000), valores inadequados de $\mathrm{pH}$ podem causar desequilíbrios fisiológicos nas plantas, afetando a disponibilidade dos nutrientes. Para substratos com predominância de matéria orgânica, a faixa de $\mathrm{pH}$ recomendada é de 5,0 a 5,8. Em pH acima de 6,5, são esperados problemas com a disponibilidade de P. Acima de 67\% de CLU, como condicionador, o $\mathrm{pH}$ dos substratos subiu para valores acima de 7,4, o que pode explicar a redução do teor de $\mathrm{P}$ foliar. 
STRINGHETA et al. (1996), avaliando o crescimento e o florescimento de plantas de crisântemo produzidas em substrato contendo CLU e CAC, como condicionadores, observaram que os melhores resultados foram atingidos quando se utilizava, aproximadamente, $30 \%$ de CLU e $70 \%$ de CAC para a variedade Amarelo São Paulo e $70 \%$ de CLU e 30\% de CAC para a 'Puritan'.

Considerando os valores mínimos críticos de macronutrientes nas folhas de plantas de crisântemo, reportados por NELSON (1991), pode-se verificar que, com relação a N, em concentrações acima de $67 \%$, houve redução dos valores de $\mathrm{N}$, abaixo do mínimo crítico $(40,0 \mathrm{~g} / \mathrm{kg})$ (Figura 2). Essa deficiência pode explicar, ainda que parcialmente, a diminuição na produção de matéria fresca e matéria seca das folhas das duas variedades estudadas, apesar de as plantas não apresentarem outros sintomas visíveis de deficiência. Sanderson \& Martim, citados por GOGUE \& SANDERSON (1975), observaram deficiência de N, queima marginal da folha e redução na altura das plantas, no peso das hastes e no número de inflorescências de vários grupos de plantas floríferas crescidas em substratos contendo CLU. Tais sintomas não se verificaram nesse experimento. Os mesmos autores correlacionaram altas concentrações de N, P, K, Ca e Mg com maior crescimento das plantas de crisântemo. É possível que, neste
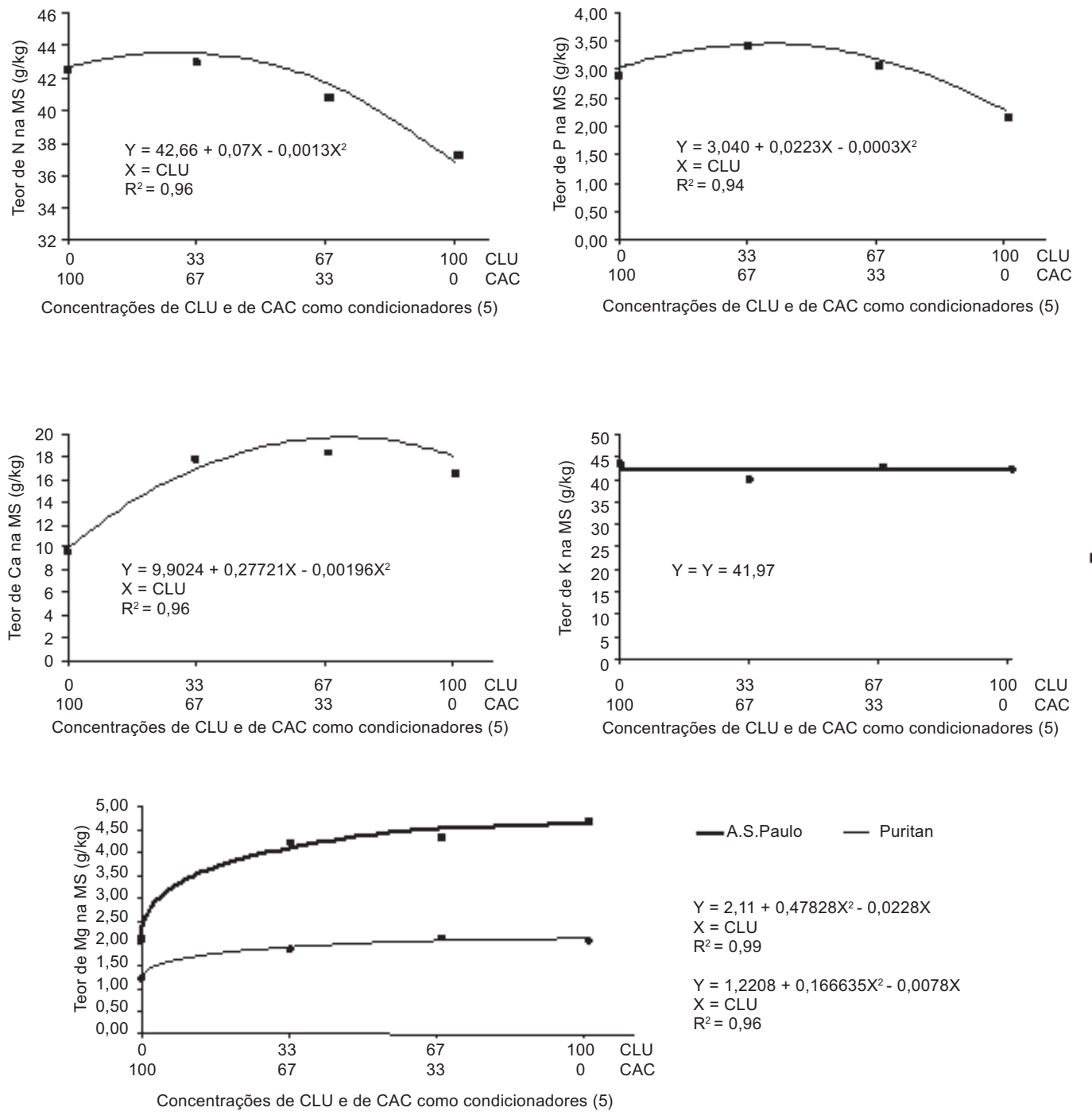

Figura 2. Teores de N, P, Ca, K e Mg na matéria seca (MS) das folhas de crisântemo, em função de concentrações de composto de lixo urbano (CLU) e casca de arroz carbonizada (CAC) como condicionadores. 
experimento, o elevado $\mathrm{pH}$ dos substratos contendo $67 \%$ e $100 \%$ de CLU tenha promovido condições de perda parcial do nitrogênio aplicado, por volatilização, como $\mathrm{NH}_{3}$.

O mesmo efeito foi observado para P. Seu teor foliar e a produção de matéria fresca e matéria seca das folhas apresentaram comportamento muito semelhante, mostrando uma relação direta entre as duas características. Acima de 67\% de CLU, o teor foliar de P ficou abaixo do mínimo crítico para a cultura $(3,0 \mathrm{~g} / \mathrm{kg})$, o que se pode explicar pelo elevado $\mathrm{pH}$ dos substratos, o que poderia ocasionar sua baixa disponibilidade para as plantas. Segundo BRADY (1989), em pH acima de 7,0 , o excesso de cálcio poderá favorecer a formação de complexos fosfatos de cálcio insolúveis, o que poderia prejudicar a absorção de $\mathrm{P}$ e Ca e a sua utilização pelas plantas. Conforme o mesmo autor, a disponibilidade de $\mathrm{K}$ também poderá ser reduzida em $\mathrm{pH}$ acima de 7,0, ocorrendo maior fixação do K pelos substratos. Entretanto, neste trabalho, a elevação do $\mathrm{pH}$ com o aumento da concentração do CLU, como condicionador, não interferiu na concentração do $\mathrm{K}$ foliar. Por outro lado, os teores de $\mathrm{Ca}$ e $\mathrm{K}$ foliares, para todos os tratamentos, permaneceram acima dos mínimos críticos, de $10,0 \mathrm{~g} / \mathrm{kg}$ e $35,0 \mathrm{~g} / \mathrm{kg}$ respectivamente.

$\mathrm{Na}$ avaliação do $\mathrm{Mg}$, no entanto, pôde-se observar comportamento diferenciado entre as variedades. A 'Amarelo São Paulo' apresentou teores acima do limite crítico mínimo $(3,0 \mathrm{~g} / \mathrm{kg})$ para os tratamentos com mais de $33 \%$ de CLU, como condicionador. Entretanto, para a 'Puritan', apesar de os teores de Mg foliar se elevarem à medida que a concentração de CLU aumentava, para todos os tratamentos estudados, os valores estiveram abaixo do limite mínimo crítico, considerados por JONES JÚNIOR et al. (1991), por NELSON (1991) e do obtido por KAGEYAMA \& KONISHI (1992) e por KAGEYAMA et al. (1993), em estudos com soluções nutritivas com níveis elevados de $\mathrm{K}$; isso indica que esta variedade é menos exigente em magnésio, uma vez que não se observaram sintomas dessa deficiência .

Trabalhando com folhas de crisântemo, GOGUE (1970) verificou correlação negativa entre $\mathrm{Mg}$ e K e que altos níveis de $\mathrm{Mg}$, no substrato, podem influenciar a absorção de nutrientes, reduzindo a concentração de K foliar. Esse efeito não foi observado no presente trabalho, em que o teor de $\mathrm{K}$ foliar manteve-se constante para todos os tratamentos, independentemente da concentração de $\mathrm{Mg}$, de CLU, ou do pH dos diferentes substratos estudados.
Os valores de $\mathrm{pH}$ e da condutividade elétrica (Tabela 2) aumentaram com a elevação da concentração do CLU e com a redução da concentração da CAC, atingindo valores bastante elevados, suficientes para interferir na disponibilidade dos nutrientes para as plantas e em sua absorção por elas. O elevado valor do $\mathrm{pH}$ foi atribuído, principalmente, à alta concentração de bases trocáveis como $\mathrm{Ca}^{2+}, \mathrm{Mg}^{2+}$ e K+ $\mathrm{K}^{+}$, presentes no CLU, o que está de acordo com KIEHL (1985). O pH para o cultivo do crisântemo deve estar na faixa de 5,5 a 7,0. Observou-se, neste trabalho, para os tratamentos $\mathrm{T}_{3} \mathrm{e}$ $\mathrm{T}_{4}$, nas duas variedades, valores acima do limite recomendado para a cultura.

Como mencionado, a condutividade elétrica (CE) do extrato aquoso também aumentou com a elevação da concentração do CLU como condicionador, em detrimento da CAC. Segundo BRADY (1989), valores acima de $4 \mathrm{dS} / \mathrm{m}$ caracterizam solos salinos. $\mathrm{O}$ tratamento $\mathrm{T}_{4}$ apresentou valor de $10,92 \mathrm{dS} / \mathrm{m}$, muito acima do limite discutido. Testando o uso de composto de lixo urbano como substrato para plantas em vaso, GOGUE \& SANDERSON (1975) e VLEESCHAUWER et al. (1980) verificaram que, em misturas até com $50 \%$ do composto, o crescimento das plantas era semelhante ou maior do que em substratos padrões. Pennigsfeld, citado por KÄMPF (2000), afirma que o crisântemo apresenta baixa sensibilidade à concentração salina dos substratos de cultivo.

A redução do teor foliar de nitrogênio, assim como os decréscimos nos de $\mathrm{P}$ e $\mathrm{Ca}$, para ambas as variedades, e de Mg para a 'Puritan', indicam que a competição entre cátions $\mathrm{K}, \mathrm{Ca}$ e $\mathrm{Mg}$ não tiveram papel preponderante na restrição do crescimento e da qualidade, com o uso de concentrações elevadas de CLU, e que, provavelmente, a elevação da conduti-vidade elétrica e/ou a presença de íons tóxicos possam ter sido mais importantes.

\section{CONCLUSÕES}

1. A maior taxa de crescimento, expressa pela produção de matéria fresca (MFFo) e de matéria seca (MSFo) das folhas, foi atingida com, aproximadamente, $50 \%$ de CLU e CAC, na fração condicionador.

2. Com $30 \%$ de CLU e $70 \%$ de CAC, como condicionadores, observaram-se concentrações de N, P, K e $\mathrm{Ca}$ foliares acima dos limites mínimos para as duas variedades. 
3. Para a variedade Puritan, a fertirrigação deverá ser suplementada com Mg, uma vez que, as concentrações foliares para todos os tratamentos estiveram abaixo do mínimo crítico considerado para a cultura do crisântemo (menor do que $3,0 \mathrm{~g} / \mathrm{kg}$ ).

4. Não se observaram sintomas de toxicidade por nutrientes nas folhas das variedades Amarelo São Paulo e Puritan.

\section{REFERÊNCIAS BIBLIOGRÁFICAS}

BRADY, N.C. Natureza e propriedades dos solos. 7.ed. Rio de Janeiro: Freitas Bastos, 1989. 878 p.

BRAGA, J.M. \& DEFELIPO, B.V. Determinação espectrofotométrica de fósforo em extratos de solo e plantas. Ceres, Viçosa, v.21, p.73-85, 1974.

DEFELIPO. B.V. \& RIBEIRO, A.C. Análise química do solo (Metodologia). Viçosa, UFV, Impr. Univ., 1996. 17p. (Boletim de Extensão no29.)

EMBRAPA. Serviço Nacional de Levantamento e Conservação dos Solos. Manual de Método de Análises do Solo. Rio de Janeiro: EMBRAPA, 1997. 212p.

GOGUE, G.J. Boron, sodium and zinc tolerance of chrysanthemums grown in processed garbage amended media. Auburn: Auburn Univ., 1970. 105p. (Tese em Magister Science.)

GOGUE, G.J. \& SANDERSON, K.C. Municipal compost as a medium amendment for chrysanthemum culture. Journal of the American Society for Horticultural Science, v.100, n.3, p.213-216, 1975.
JONES JUNIOR, J. B.; WOLF, B. \& MILLS, H. A. Plant analysis handbook. Georgia: Micro-Macro Pub., 1991. $213 \mathrm{p}$.

KAGEYAMA, Y. \& KONISHI, K. Effect of phosphorus application in hydroponic solution on growth and phosphorus uptake in chrysanthemum plants. Journal of the Japanese Society Horticultural Science, v.61, n.3, p.635-642, 1992.

KAGEYAMA, Y.; NAKAGAMA, Y. \& KONISHI, K. Potassium application to chrysanthemuns grown hidroponically for cut flower production. Journal of the Japanese Society Horticultural Science, v.61, n.4, p.895-900, 1993.

KÄMPF, A. N. Produção comercial de plantas ornamentais. Guaíba: Agropecuária, 2000. 254 p.

KIEHL, E. S. Fertilizantes orgânicos. São Paulo: Agronômica Ceres, 1985. 492 p.

NELSON, P. V. Fertilization. In: Greenhouse Operation and Management. New Jersey: Prentice Hall, 1991. p.306-308.

SOUZA, M.M. Efeito de substratos em diferentes proporções no cultivo, em vasos, de "Chrysanthemum morifolium Ramat". Viçosa, MG: UFV, 1991.69 p. (Tese de Mestrado.)

STRINGHETA, A.C.O.; FONTES, L.E.F.; LOPES, L.C. \& CARDOSO, A. A. Crescimento de crisântemo em substrato contendo composto de lixo urbano e casca de arroz carbonizada. Pesquisa Agropecuária Brasileira, Brasília, v.31, n.11, p.795-802, 1996.

VLEESCHAUWER, D.; VERDONCK, O. \& DE BOODT, M.. The use of a town refuse compost in horticultural substrates. Acta Horticulturae, Wageningen v.99, p.149155,1980 . 